\title{
Experimental investigation on engineering properties of lightweight foamed concrete (LFC) with coconut fiber addition
}

\author{
Nabihah Mohd Zamzani ${ }^{1}$, Md Azree Othuman Mydin ${ }^{1, *}$, Abdul Naser Abdul Ghani ${ }^{1}$ \\ ${ }^{1}$ School of Housing, Building and Planning, Universiti Sains Malaysia, 11800, Penang, Malaysia
}

\begin{abstract}
In the last few years, there is emerging attention in using Lightweight Foamed Concrete (LFC) as a lightweight non-structural and semi-structural element in buildings to take advantage of its excellent insulation properties. Though, LFC has been noticed to have some disadvantages: considerable brittleness; results in low compressive and flexural strength, poor fracture toughness, poor resistance to crack propagation and low impact strength. Coconut fibre obtained from coconut husk, belonging to the family of palm fibres, is agricultural waste products obtained in the processing of coconut oil. In Malaysia, they are available in large quantities. Coconut fibre is extracted from the outer shell of a coconut. There are many general advantages of coconut fibres e.g. they are moth-proof, resistant to fungi and rot, provide excellent insulation against temperature and sound, not easily combustible, flame-retardant, unaffected by moisture and dampness, tough and durable, resilient, springs back to shape even after constant use, totally static free and easy to clean. Hence this study is intended to look into the potential of coconut fiber in enhancing the engineering properties of LFC. There are 5 engineering properties will be focused in this study which are flexural strength, splitting tensile strength, compressive strength, Poisson's ratio and Poisson's ratio toughness. Three densities of LFC of $800 \mathrm{~kg} / \mathrm{m}^{3}, 1100$ $\mathrm{kg} / \mathrm{m}^{3}$ and $1400 \mathrm{~kg} / \mathrm{m}^{3}$ were cast and tested. The ratio of cement, sand and water used in this study was 1:1.5:0.49. Coconut fibers were used as additives at $0.12 \%, 0.24 \%, 0.36 \%, 0.48 \%$ and $0.60 \%$ by volume of the total mix. Test results indicated that the engineering properties of LFC strengthen with coconut fiber had increased soundly. Coconut fiber inclusion changes the post-peak response at the load-deflection curves for the samples, which modifies the failure mode and enhance the flexural strength, compressive strength and splitting tensile strength.
\end{abstract}

\section{Introduction}

Green environment is a puzzling and stimulating concern to achieve in today's construction industry [1]. The call for green concrete technology is impelled by amplified rules and guidelines in turn to minimize the greenhouse gas emission and lessening the carbon

\footnotetext{
*Corresponding author: azree@usm.my
} 
footprint [2]. Furthermore, the construction industry in Malaysia is embracing green construction owing to project requirements for Green Building Index (GBI) certification [3]. As far as GBI rating tool is concerned, it was first introduced in Malaysia back in year 2005 in which the main objective was to enhance awareness among industrial players and to encourage sustainable construction in the built environment [4]. Global apprehension and governance on carbon footprint emissions has driven research into green concrete throughout the world which special attention been given on environmental deliberations with respect to base mix material sourcing, concrete mix design, design of structural component, construction method, construction technology and last but not least the aspect of concrete structure maintenance [5]. Hence, the concrete industry players in Malaysia can play a huge role towards achieving sustainable development of the society holistically [6].

Lightweight Foamed Concrete (LFC) is good in compression but relatively weak in tension and tends to be brittle [7]. As the density decreases, the formation of air bubbles and the interrelation of them increases significantly. Therefore, water vapor increases and lead to reduction in LFC strength. However, the weakness in tension can be reduced by the inclusion of adequate volume of certain fibers [8]. The use of fibers could arrest cracks formation and improve strength and ductility yet improving its toughness.

There are numerous studies that prove the effectiveness of fibers into mixtures in the aspects of durability and mechanical properties enhancement. Fibers can be separated into two which are the synthetic known as man-made fibers and natural fibers known to be more environmental friendly and they have their own advantages and disadvantages [9]. The finest fibers have a very good essence that assist to enhance the strength and properties of concrete. The use of natural fiber can help for the improvement of shrinkage and ductility [10].

There are extensive researches have been carried out in the understanding and applications of coconut fiber in concrete based materials all over the world. These undertakings embrace, the progress of new, stronger fibers, better fiber strengthened concrete and new alternatives. In general, coconut fiber fibers haves been used to enhance concrete and mortar strengths and durability performance and has proven to improve the toughness of the concrete and mortar holistically [11]. However, the problem of long term durability has not yet been solved. It has also been noticed that the degree of strength enhancement of concrete by coconut fiber fibers addition depends on the type of the species and ages of the fiber itself. The capability of fibers can be defined from their act when they receive force from compression, flexural and tensile strengths. Hence this research attempts to evaluate the potential use of coconut fiber to enhance mechanical performance of LFC.

\section{Methodology}

The mix constituents included Ordinary Portland cement (OPC), fine aggregate, clean water and surfactant. The LFC mixture's proportion of cement, sand and water is 1:1.5:0.49. The target densities were $1050 \mathrm{~kg} / \mathrm{m}^{3}$ and $1350 \mathrm{~kg} / \mathrm{m}^{3}$. The water-cement ratio was set up at 0.49. Coconut fiber was used as filler in LFC with $0.12 \%, 0.24 \% .0 .36 \%, 0.48 \%$ and $0.60 \%$ by total volume of mix. The coconut fibers were cut into $19 \mathrm{~mm}$ length. Water absorption test, porosity test, ultrasonic pulse velocity test and compression test on cube were conducted which will be explained in the following section.

\subsection{Water absorption test}

Water absorption test was carried out in this study to calculate the water absorption capacity of hardened lightweight foamed concrete in accordance with BS 1881-122. Prior to the testing, the specimen cubes $(100 \mathrm{~mm} \times 100 \mathrm{~mm} \times 100 \mathrm{~mm})$ were taken out one day 
in advanced from the curing tank. The specimen was wiped to surface dry condition and weighed to obtain the saturated surface dry weight of the specimen. Next, the specimen was oven dried for one day and the oven dried weight of specimen was measured.

\subsection{Vacuum Saturation test}

Porosity and permeability of LFC are interconnected. Porosity determines the pathway of intrusion of aggressive ions such as carbonates and chloride into the concrete. Permeability determines the rates of intrusion. Porosity was determined by the existence of pores, capillary pores, micro-cracks, Interfacial Transition Zone (ITZ) and porosity in filler. Permeability was determined by the total porosity of the LFC. In this study, the permeability sample was used to determine the porosity after completing the intrinsic permeability test. Porosity was determined by water absorption under vacuum condition. The LFC specimens were weighted as their dried mass after completing intrinsic permeability test. The sample was then put into a desiccator full of water. The desiccator was sealed tightly with super sticky grease. A vacuum pump was connected to the desiccator to vacuum away all the existing gas inside the desiccators. The system was allowed to run for $72 \pm 2$ hours. The saturated specimens were weighted in air and suspended in water. The porosity was calculated by the following formula.

\subsection{Ultrasonic Pulse Velocity test}

Ultrasonic pulse velocity is the non-destructive test to know the concrete characterization. The ultrasonic wave is generated by a transducer in contact with the test material either in the form of compressional wave or shear wave. These waves are detected by the second transducer placed on the other face of the test material. The ultrasonic wave velocity depends on the elastic properties and density of the concrete (ACI 544.1R, 1996). The travel time and energy decay through the material have been processed and displayed by the digital computer connected with the transducers. Using the travel time and measured dimension, the ultrasonic pulse velocity has been calculated.

\subsection{Axial Compression test}

The compressive strength test was conducted by using compressive strength machine. The test was performed in accordance with BS EN 12390-3:2009 (2002) using a cube specimen size of $100 \mathrm{~mm} \times 100 \mathrm{~mm} \times 100 \mathrm{~mm}$. An axial compressive load with a loading rate of $0.2 \mathrm{~N} / \mathrm{sec}$ was applied to $100 \mathrm{~mm}$ cube until failure occurred. Go Tech GT-7001-BS300 universal testing machine with capacity of $3000 \mathrm{kN}$ was used to perform this compression test on the specimens. The result was taken at 7, 28, 60 day of age. Mean value attained from 3 specimens was then taken as cube compressive strength for each LFC mix. Figure 5 shows the Go Tech GT-7001-BS300 universal testing machine.

\section{Results and Discussion}

This section presents the results obtained from experimental works which will cover 4 main findings which are water absorption, porosity, ultrasonic pulse velocity and axial compressive strength. 


\subsection{Water Absorption}

Figure 1 shows the influence of different coir fiber percentages in LFC on water absorption capacity. From Figure 1, the study reveals that moisture absorption capability was decreased by increment of coir fiber percentages in LFC. Higher fiber contents absorb water slower at the initial stage compare to lower percentages. It could achieve saturation level slower [12]. The higher density $\left(1350 \mathrm{~kg} / \mathrm{m}^{3}\right)$ with higher percentage of fiber content consists of a small volume and size of pores which can avoid water penetrating into the specimen. While due to drying process the fiber loses the moisture and shrinks back onto their sizes. There are fine void in the specimen and concrete can absorb the water. So that, it can be expected that the absorption will decreases along with the age of the sample.

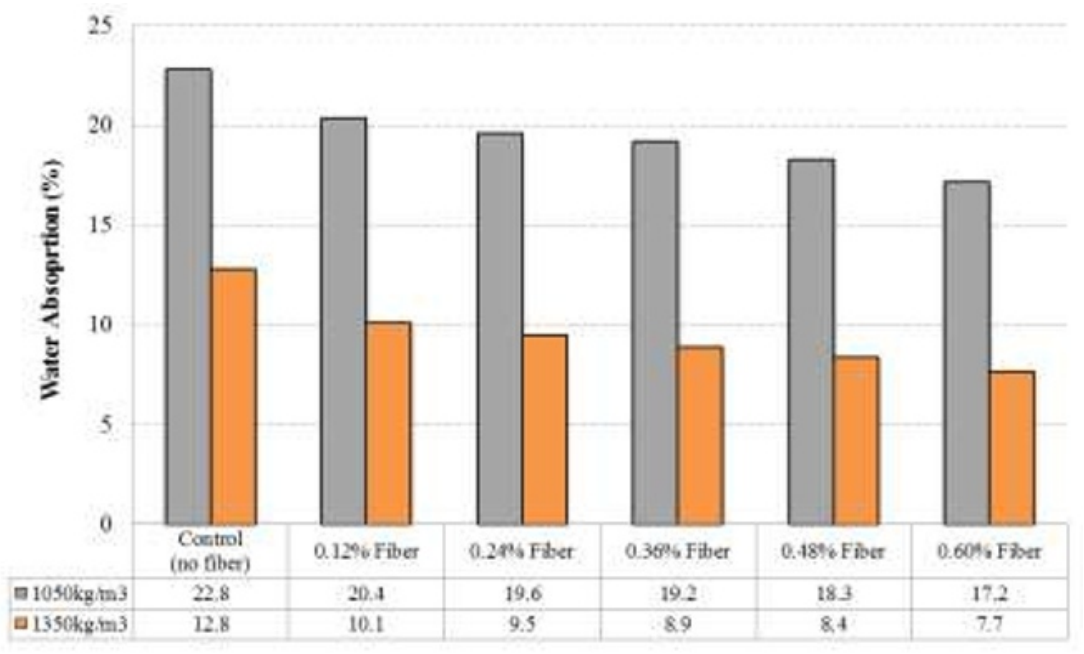

Fig. 1. Water absorption of LFC with different filler (coconut fiber) percentages.

\subsection{Porosity}

Figure 2 demonstrates the influence of different coir fiber percentages in LFC on porosity. From Figure 2, it can be clearly seen that the porosity of LFC decreased by increment of coir fiber percentages in LFC for both densities. The reduction in porosity of LFC was triggered by alteration and variation of morphology of the coconut fiber. Fiber was not truly mono-filament hence it was a pack of mono-filament attached and enclosed by lignin [13]. From Figure 2, the high density LFC $\left(1350 \mathrm{~kg} / \mathrm{m}^{3}\right)$ exhibited a low percentage of porosity while the low-density LFC $\left(1050 \mathrm{~kg} / \mathrm{m}^{3}\right)$ produced a high percentage of porosity. The foam allows air into the mix slurry during the mixing process. A high quantity of foam lets air voids into the mix to lessen its density. Hence, low density LFC necessitates more foam, therefore leading to higher value of porosity. Then, the high percentage of porosity reduces the compressive strength by increasing the amount of voids. This will create a weak cell structure between the pores and the matrix as there is insufficient surface area that connects the pores and the matrix. Also, at this density the binding materials are limited due to the high inclusion of foam, so that the setting and hardening of the LFC is delayed. It affects 
the strength of the LFC, which is not strong enough upon drying; hence, the collapsing of LFC occurs.

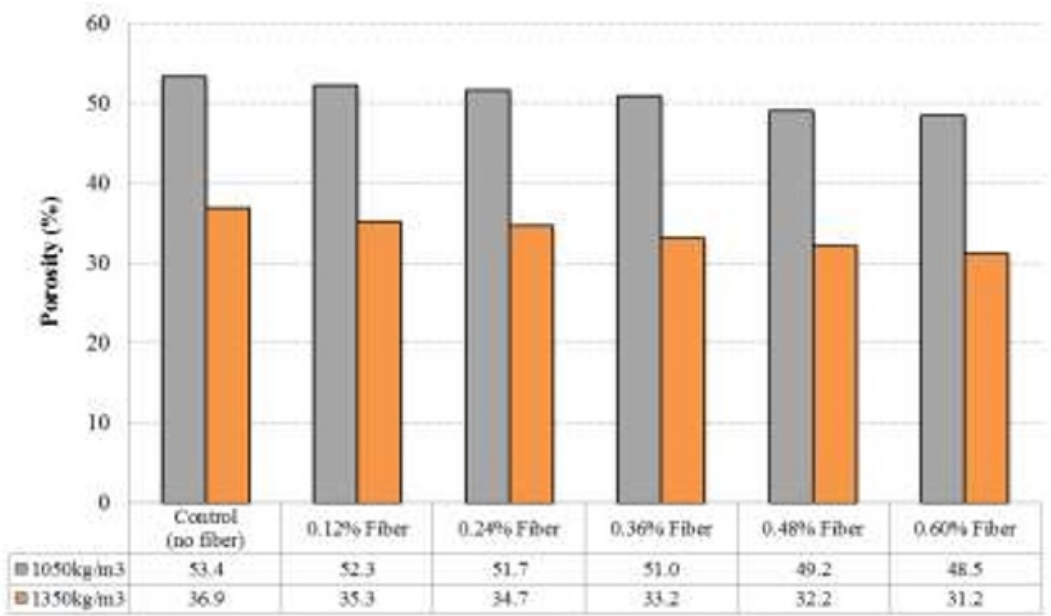

Fig. 2. Porosity of LFC with different filler (coconut fiber) percentages.

\subsection{Ultrasonic Pulse Velocity (UPV)}

Ultrasonic pulse velocity (UPV) is one of the most prevalent non-destructive methods implemented to evaluate concrete toughness. Though it is not a precise apparatus to measure the pore structures in concrete, but it can still provide an excellent initial forecast of the quality of concrete based material. Figure 3 shows the ultrasonic pulse velocity (UPV) results for both densities tested in this study. It can be seen from Figure 3 that higher addition of coir fiber in the base mix has enhanced the ultrasonic pulse velocity (UPV) in comparison with control specimen. For both densities, $0.6 \%$ coconut fiber inclusion gave an excellent ultrasonic pulse velocity (UPV) reading of $2510 \mathrm{~m} / \mathrm{s}$ for $1050 \mathrm{~kg} / \mathrm{m}^{3}$ density and $3421 \mathrm{~m} / \mathrm{s}$ for $1350 \mathrm{~kg} / \mathrm{m}^{3}$. This might be associated to the hydration mechanism of the binary cementitious system in LFC for fiber with higher percentages of coconut fiber in the base mix [14].

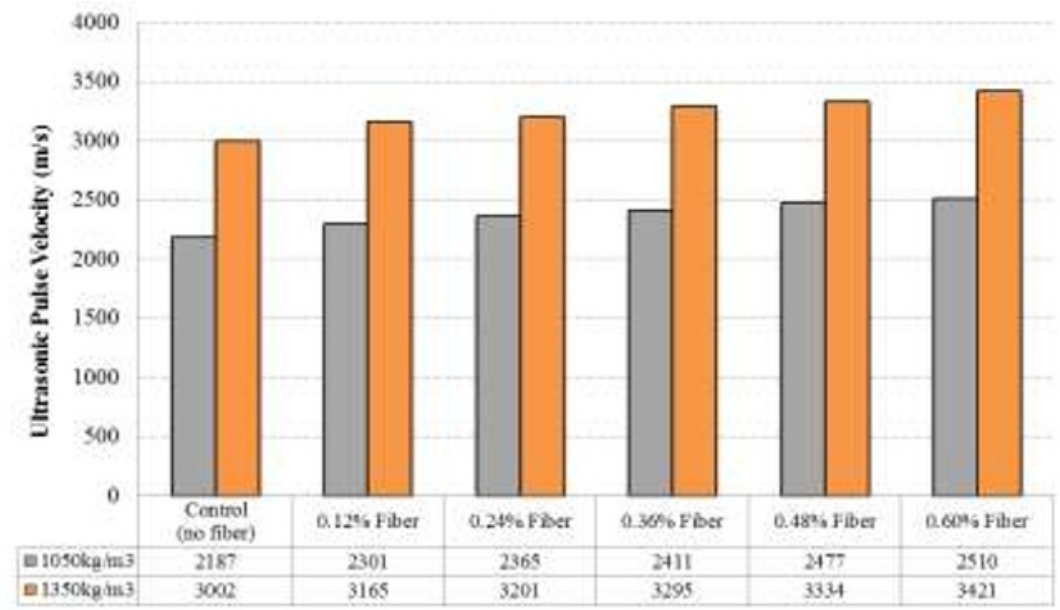

Fig. 3. Ultrasonic pulse velocity (UPV) of LFC with different filler (coconut fiber) percentages. 


\subsection{Axial Compressive Strength}

Figures 4 and 5 display the axial compressive strength results for $1050 \mathrm{~kg} / \mathrm{m}^{3}$ and 1350 $\mathrm{kg} / \mathrm{m}^{3}$ densities in that order. From both figures, it can be clearly seen that $0.36 \%$ addition of coconut fiber in LFC mix contributed to remarkable axial compressive strength results compared to control specimen and other percentages of coconut fiber which were 4.1 $\mathrm{N} / \mathrm{mm}^{2}$ for $1050 \mathrm{~kg} / \mathrm{m}^{3}$ density and $7.6 \mathrm{~N} / \mathrm{mm}^{2}$ for $1350 \mathrm{~kg} / \mathrm{m}^{3}$ at 28-day. Addition of $0.36 \%$ of coconut fiber in the base mix reinforces the bonding between the fiber and the cement matrix [15]. It has been observed that the higher density of LFC produces high axial compressive strength, while low density gains lower strength as can be observed in Figure 4 and Figure 5. As expected, the density of the LFC influenced by its porosity had significant effects on the compressive strength of LFC.

Air voids, pores and matrix which attribute to the microstructure normally will influence the compressive strength which is in relation to the density. The development of the compressive strength of the LFC specimens was observed to increase over the testing ages. Coconut fiber is a natural fiber that contributes on the axial compressive strength. The fibers would not cause the specimen to break apart but will react as an anti-micro crack agent which would have prevented the cracks from widening. Since coir fiber has a higher modulus, the higher concentration of fibers need more stress.

It should be pointed out that coconut fiber is a reinforcing agents because of their biodegradable characteristics. Naturally, coconut fiber has higher failure strain which can provide a better compatibility between the fibers and the matrix. As the fiber content increases, the degree of obstruction increases and this will cause the hardness to increase. The short length fibers will hold the particles stronger. The coconut fibers fibres were capable of absorbing energy because of the strong particle bonding between the fiber and the matrix. The strength increased linearly with the addition of coconut fiber up to $0.36 \%$ in the mixtures and it is expected to be further increased if the testing ages were extended.

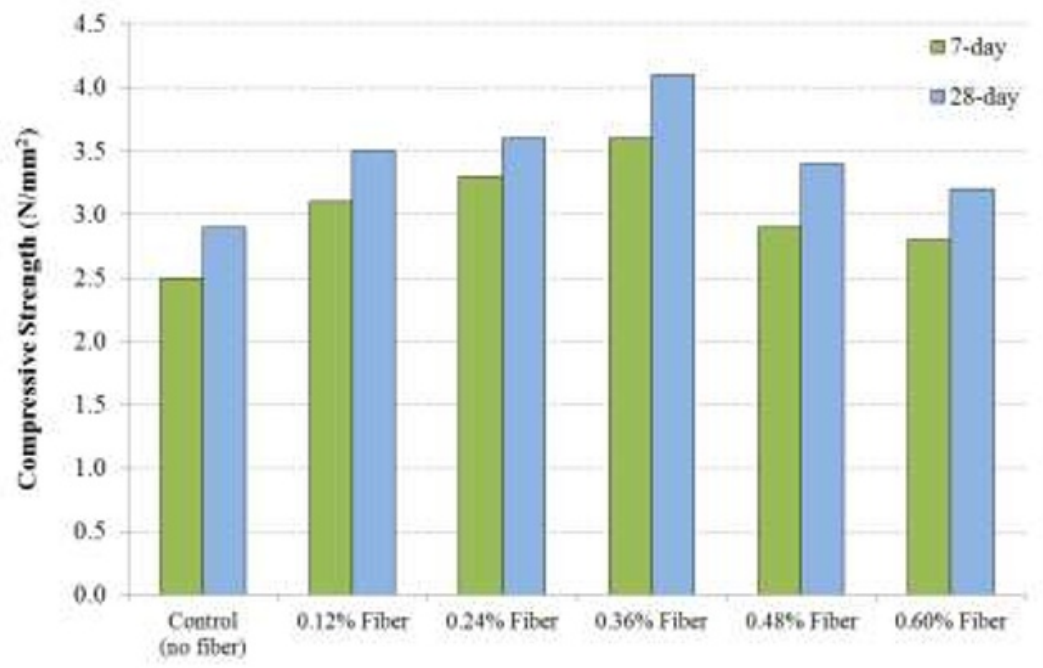

Fig. 4. Compressive strength of LFC for $1050 \mathrm{~N} / \mathrm{mm}^{2}$ density. 


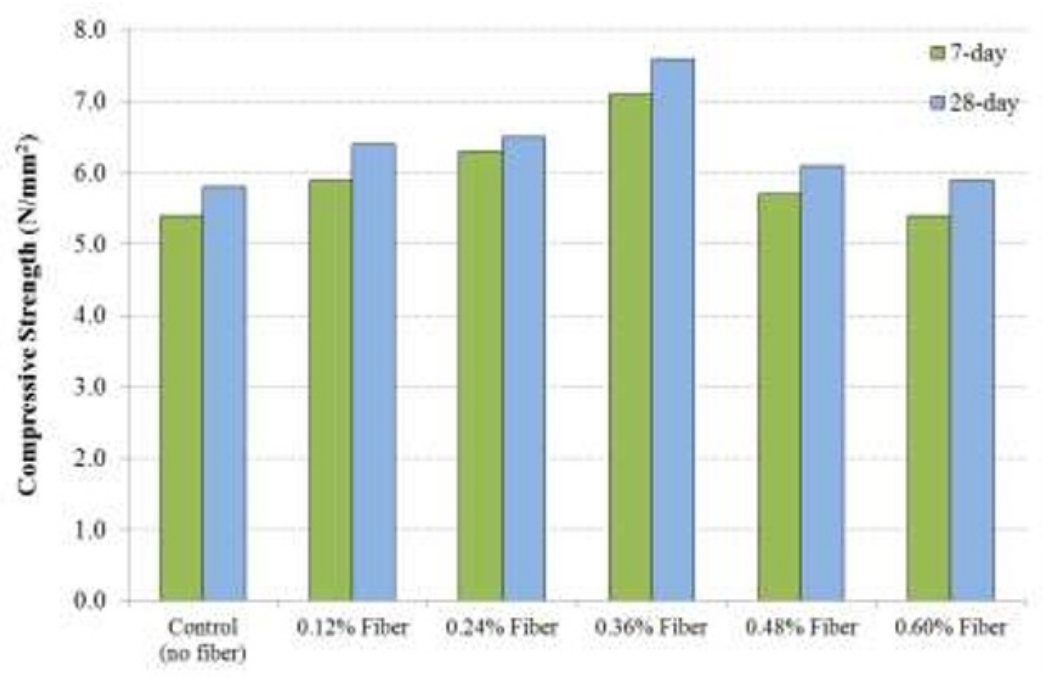

Fig. 5. Compressive strength of LFC for $1350 \mathrm{~N} / \mathrm{mm}^{2}$ density.

\section{Conclusion}

An experimental study was conducted to evaluate the potential use of coconut fiber reinforced lightweight foamed concrete in terms of its mechanical properties. The study reveals:

1. Moisture absorption capability was decreased by increment of coir fiber percentages in LFC. Higher fiber contents absorb water slower at the initial stage in comparison to lower fiber percentages.

2. The reduction in porosity of LFC was triggered by alteration and variation of morphology of the coconut fiber. Fiber was not truly mono-filament hence it was a pack of mono-filament attached and enclosed by lignin.

3. Higher addition of coir fiber in the base mix has enhanced the ultrasonic pulse velocity (UPV) in comparison with control specimen. For both densities, $0.6 \%$ coconut fiber inclusion gave an excellent ultrasonic pulse velocity (UPV) reading. This might be connected to the hydration contrivance of the binary cementitious system in LFC for fiber with higher percentages of coconut fiber in the base mix.

4. Addition of $0.36 \%$ coconut fiber in LFC mix contributed to remarkable axial compressive strength results compared to control specimen and other percentages of coconut fiber. Inclusion of coconut fiber in the base mix reinforces the bonding between the fiber and the cement matrix

5. Coconut fiber inclusion changes the post-peak response at the load-deflection curves for the samples, which modifies the failure mode and enhances the compressive strength.

The author would like to thank Ministry of Higher Education Malaysia for their funding of this research under Fundamental Research Grant Scheme (Grant No. 203/PPBGN/6711514) with research title: Fundamental Study to Establish Thermal Insulation, Mechanical Properties and Fire Retardant Mechanism of Coir Fibre Reinforced Lightweight Foamcrete. 


\section{References}

1. E.P. Kearsley, P.J. Wainwright, Cem. Concr. Res., 32, 241-246 (2002)

2. M.A.O. Mydin, N. Utaberta, Int. J. of Applied Eng. Research, 10(17), 37846-37850 (2015)

3. N. Narayanan, K. Ramamurthy, Cem. Concr. Res., 30, 457-464 (2000)

4. M.A.O. Mydin, Int. J. Tech., 8(5), 800-810 (2017)

5. E.K. Kunhanadan Nambiar, K. Ramamurthy, Cem. Concr. Res., 37, 1341-1347 (2007)

6. G. Yakovlev, J. Kerienè, A. Gailius, I. Girnienè, Materials Science, 12(2), 147-151 (2006)

7. M.A. Othuman Mydin, J. Teknol., 78(5), 477-482 (2016)

8. J. Zhou, S. Bai, C. Bian, Appl. Mech.Mater., 513-517, 16-19 (2014)

9. M.A Othuman Mydin, J. Teknol., 78(5), 413-419 (2016)

10. A. Domingo-Cabo, C. Lazaro, F. Lopez-Gayarre. Const. Bldg. Mater. 23, 2545-2553 (2009)

11. M.A. Othuman Mydin, J. Teknol., 78(5), 431-435 (2016)

12. K. Jitchaiyaphum, T. Sinsiri, P. Chindaprasirt, Procedia Engineering, 14, 1157-1164, (2011)

13. A.H. Ameer, H.T. Nicholas, R.D. Andrew, IACSIT Int. J. of Eng. Tech, 7(4), 286-293 (2015)

14. A. O. Mydin, S. Soleimanzadeh, Adv. Appl. Sci. Res., 3(5), 2837-2846 (2012)

15. J.M. Chi, R. Huang, C.C. Yang, J.J. Chang, Cem. Concr. Compos., 25, 197-205 (2003) 